\title{
ÍNDICES DE SELEÇÃO PARA IDENTIFICAR GENÓTIPOS DE SORGO GRANÍFERO TOLERANTES AO ESTRESSE HÍDRICO
}

\author{
PAULO SÉRGIO CARDOSO BATISTA ${ }^{1}$, JOSÉ SEBASTIÃO CUNHA FERNANDES ${ }^{1}$, \\ ARLEY FIGUEIREDO PORTUGAL ${ }^{2}$, LUANNA VANESSA DE SOUZA CANGUSSÚ ${ }^{3}$, \\ MARCOS PAULO MINGOTE JULIO ${ }^{4}$, CICERO BESERRA DE MENEZES ${ }^{2}$
}

\author{
${ }^{1}$ Universidade Federal dos Vales do Jequitinhonha e Mucuri, Diamantina - MG, BR, \\ paulosergiocardoso@yahoo.com.br,jsc11912@gmail.com \\ ${ }^{2}$ Embrapa Milho e Sorgo, Sete Lagoas - Minas Gerais, BR, cicero.menezes@embrapa.br,arley.portugal@embrapa.br \\ ${ }^{3}$ Universidade Estadual de Montes Claros, Janaúba-MG, BR, luanna-cangussu@hotmail.com \\ ${ }^{4}$ Universidade Federal de São João del-Rei, Sete Lagoas, MG, BR, marcospmj@yahoo.com.br
}

$\overline{\text { Revista Brasileira de Milho e Sorgo, v.18, n.3, p. 379-395, } 2019}$

\begin{abstract}
RESUMO - O objetivo deste trabalho foi avaliar a eficiência de diferentes índices na identificação de híbridos de sorgo granífero adaptados aos ambientes com e sem estresse hídrico. Foram avaliados 16 híbridos em ambientes com e sem estresse hídrico, em três anos de cultivo, em Nova Porteirinha-MG. Nos ensaios com estresse hídrico, a irrigação foi suspensa aos 45 dias após a semeadura, pouco antes do florescimento. Nos ensaios sem estresse hídrico os híbridos foram irrigados até a maturação fisiológica dos grãos, 85 dias após a semeadura. Os índices de tolerância à seca por híbrido foram calculados com base no rendimento de grãos por parcela para os ambientes com estresse hídrico, sem estresse hídrico e significância do rendimento de grãos em condições com estresse e sem estresse hídrico. O estresse hídrico proporcionou redução no rendimento de grãos nos três anos de cultivo. Os índices MP (produtividade média), GMP (produtividade média geométrica) e MRP (desempenho relativo médio) foram adequados para seleção de genótipos de sorgo tolerantes ao estresse hídrico pós-florescimento.
\end{abstract}

Palavras-chave: Sorghum bicolor, rendimento de grãos, estresse hídrico, índices de tolerância.

\section{SELECTION INDICES TO IDENTIFY GRAIN SORGHUM GENOTYPES TOLERANT TO WATER STRESS}

\begin{abstract}
The objective of this work was to evaluate the efficiency of different indices in the identification of sorghum hybrids adapted to environments with and without water stress. Sixteen hybrids of sorghum were evaluated in environments with and without water stress in three crop seasons. In the trials with water stress, irrigation stoped around 45 days after sowing, close to flowering. In the trials without water stress, the hybrids were irrigated until the physiological maturity of the grains. Water stress caused a reduction in grain yield of sorghum genotypes in the three years of cultivation. The indexes average productivity, average geometric productivity and average relative performance were adequate for the selection of sorghum genotypes tolerant to water stress at post-flowering.
\end{abstract}

Keywords: Sorghum bicolor, grain yield, water stress, tolerance indices. 
Os estresses abióticos, dentre eles o estresse hídrico, ameaçam a disponibilidade global de alimentos, pois causam redução drástica no crescimento e rendimento das plantas (Xiong et al., 2006), principalmente das culturas mais suscetíveis. Assim, a utilização de culturas tolerantes ao estresse hídrico, como o sorgo (Sorghum bicolor (L.) Moench), consiste em importante estratégia para minimizar os efeitos causados pela seca em todo o planeta (Reddy et al., 2009). Segundo Blum (2004), a tolerância do sorgo à baixa disponibilidade hídrica está associada às suas características xerófitas e a mecanismos eficientes de tolerância à seca.

O sorgo destaca-se entre outras gramíneas de importância econômica não apenas pela sua tolerância ao déficit hídrico, mas também pela possibilidade de se realizar o seu cultivo em sistema de sequeiro, em épocas e locais com maior ocorrência de irregularidade na distribuição da pluviosidade (Xin et al., 2009). A produção de sorgo granífero no Brasil na safra 2017/18 foi de 2,136 milhões de toneladas, em uma área de 782,2 mil hectares, com rendimento médio de $2.731 \mathrm{~kg} \mathrm{ha}^{-1}$ (Acompanhamento da Safra Brasileira [de] Grãos, 2018).

Para melhorar o rendimento do sorgo, bem como a estabilidade de produção em ambientes ou regiões suscetíveis ao estresse hídrico, há uma necessidade de identificar técnicas de triagem capazes de distinguir genótipos com alto rendimento nesses ambientes. Assim, muitos índices foram propostos para a seleção de genótipos tolerantes à seca, com base no rendimento em ambientes com e sem estresse, visando à obtenção de genótipos estáveis, com alto rendimento e tolerantes ao déficit hídrico (Mohammadi et al., 2010; Nouri et al., 2011; Sahar et al., 2016). Dentre esses índices, destacam-se o índice de suscetibilidade ao estresse (SSI) (Fischer \& Maurer, 1978), índice relativo de seca (RDI) (Fischer \& Wood, 1979), produtividade média (MP), índice de tolerân- cia (TOL) (Rosielle \& Hamblin, 1981), produtividade média geométrica (GMP), índice de tolerância ao estresse (STI) (Fernandez, c1993), índice de resistência à seca (DI) (Lan, 1998), desempenho relativo médio (MRP), índice de eficiência relativa (REI) (Hossain et al., 1999), índices modificados de tolerância ao estresse (MSTIk1 e MSTIk2) (Farshadfar \& Sutka, 2002), média harmônica de rendimento (HM) (Dadbakhsh et al., 2011) e índice de sensibilidade à seca (SDI) (Farshadfar \& Javadinia, 2011).

Os melhores índices são aqueles que apresentam alta correlação com o rendimento de grãos, tanto nas condições de estresse hídrico como nas condições sem estresse hídrico, possibilitando a identificação de possíveis genótipos com alto rendimento e tolerância à seca (Farshadfar \& Elyasi, 2012), auxiliando na seleção de genótipos tolerantes à seca. Assim, o objetivo deste trabalho foi avaliar a eficiência de índices de seleção para tolerância à seca na identificação de híbridos de sorgo granífero adaptados aos ambientes com e sem estresse hídrico.

\section{Material e Métodos}

Os experimentos foram instalados na Estação Experimental do Gorutuba, Nova Porteirinha-MG, pertencente à Embrapa Milho e Sorgo, nos anos de 2014, 2015 e 2017. Nova Porteirinha está inserida na mesorregião do Norte de Minas, na área mineira do Semiárido brasileiro e na microrregião de Janaúba -MG. As coordenadas geográficas são $15^{\circ} 48^{\prime} 10^{\prime \prime}$ de latitude Sul e $43^{\circ} 18^{\prime} 03^{\prime \prime}$ de longitude Oeste. O clima, segundo Köppen (1931), é do tipo Aw (tropical, com inverno seco). O solo da área experimental é caracterizado como Latossolo Vermelho-amarelo de textura média. As principais ocorrências climáticas nos três anos de ensaios são apresentadas nas Figuras 1, 2 e 3. 


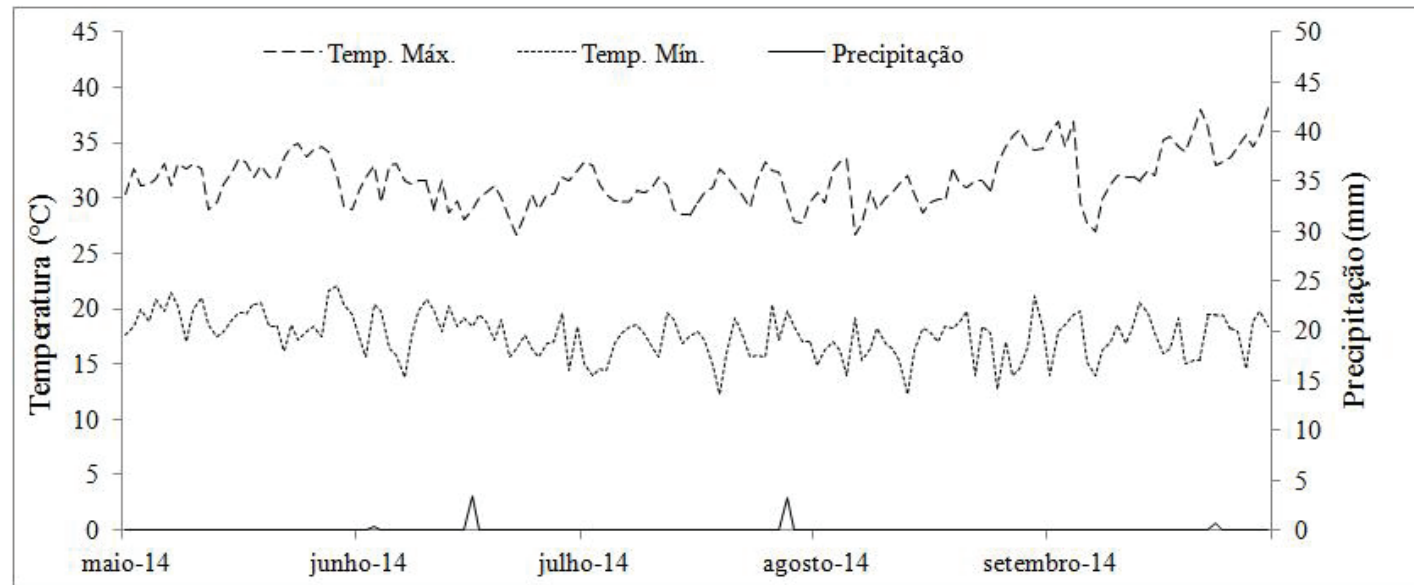

Figura 1. Ocorrências climáticas diárias de precipitação $(\mathrm{mm})$, temperatura máxima e mínima $\left({ }^{\circ} \mathrm{C}\right)$, em 2014 , em Nova Porteirinha-MG (Fonte: Instituto Nacional de Meteorologia, 2018).

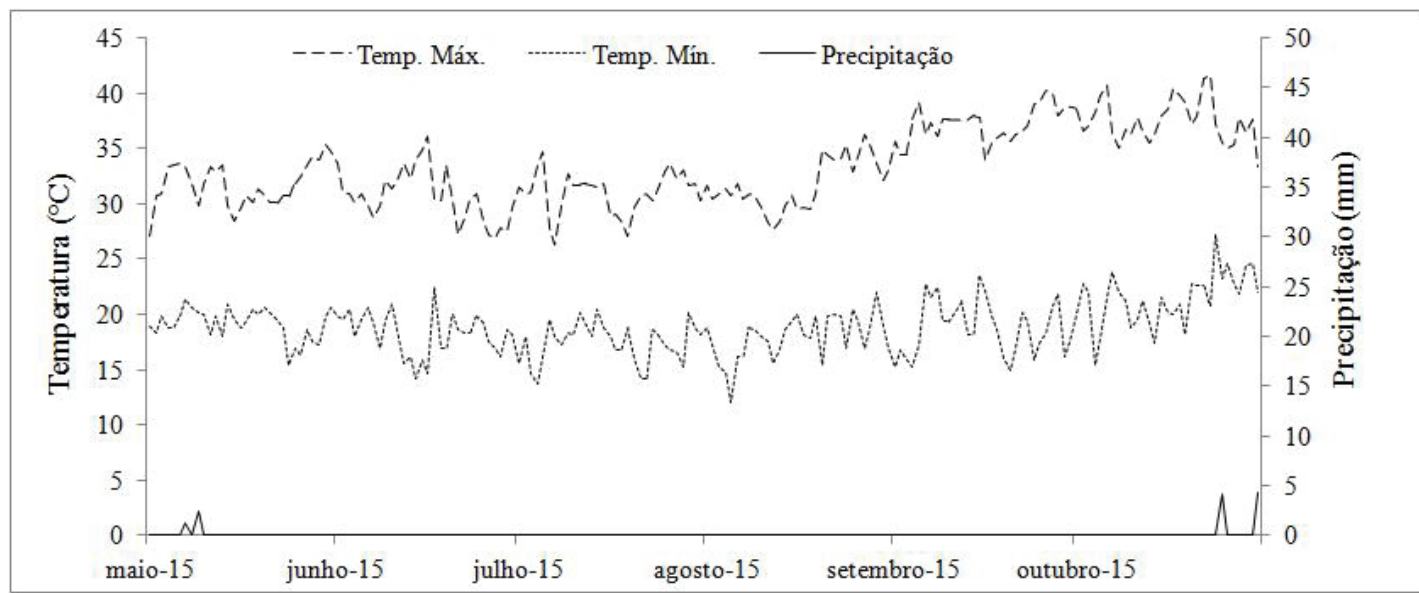

Figura 2. Ocorrências climáticas diárias de precipitação $(\mathrm{mm})$, temperatura máxima e mínima $\left({ }^{\circ} \mathrm{C}\right)$, em 2015 , em Nova Porteirinha-MG (Fonte: Instituto Nacional de Meteorologia , 2018).

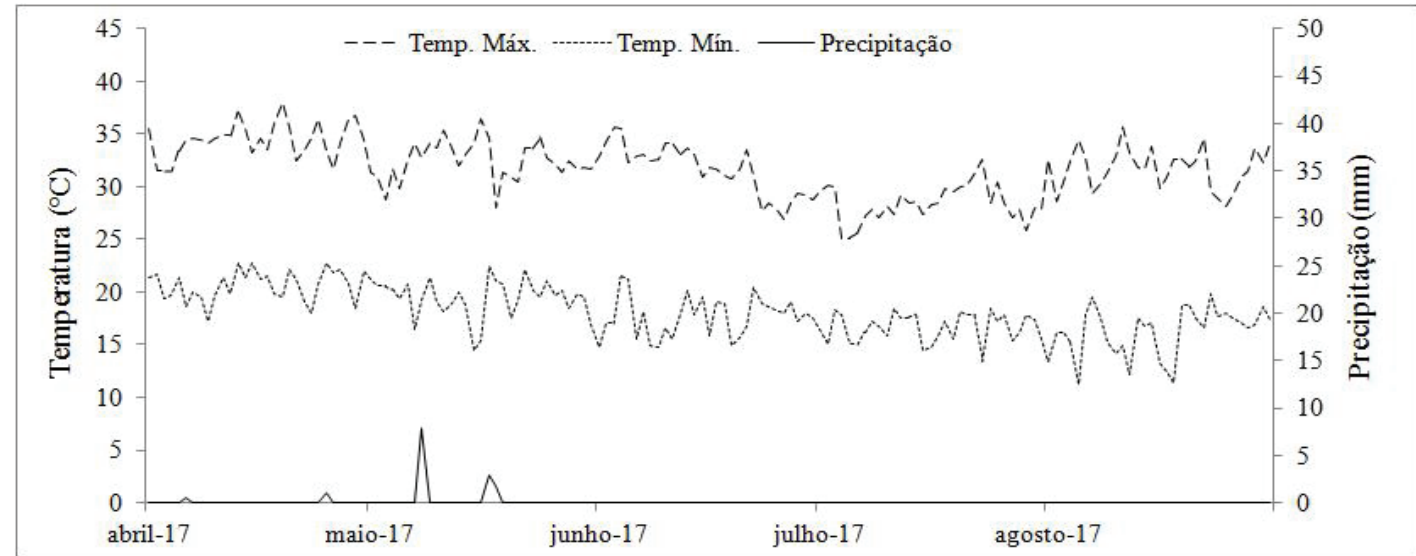

Figura 3. Ocorrências climáticas diárias de precipitação $(\mathrm{mm})$, temperatura máxima e mínima $\left({ }^{\circ} \mathrm{C}\right)$, em 2017 , em Nova Porteirinha-MG (Fonte: Instituto Nacional de Meteorologia , 2018). 
Foram avaliados 16 híbridos de sorgo granífero (BRS 310, BRS 330, BRS 332, $1 \mathrm{G} 100,1 \mathrm{G} 220,1 \mathrm{G}$ 282, 50A10, 50A70, AG 1040, AG 1080, AG 1090, AS 4625, AS 4639, DKB 590, BM 737 e 1167092), selecionados por serem os mais plantados no País na atualidade.

Os híbridos foram cultivados em ambientes com e sem estresse hídrico em três anos consecutivos. Nos ensaios com estresse hídrico, a irrigação foi cortada aos 45 dias após a semeadura, na época em que a maioria dos híbridos se encontrava no estádio de emborrachamento, para que o estresse hídrico ocorresse no início ou após o florescimento. Nos ensaios sem estresse hídrico, irrigou-se até a maturação fisiológica dos grãos, 85 dias após a semeadura. Em todos os ensaios utilizou-se irrigação por aspersão convencional, com os aspersores espaçados 12,0 x 12,0 m, pressão de serviço de $250 \mathrm{kPa}$, bocais de 4,0 x 2,6 mm de diâmetro e com vazão de $1,6 \mathrm{~m}^{3} \mathrm{~h}^{-1}$. O manejo da irrigação foi realizado com base na evapotranspiração da cultura. As lâminas de média de irrigação nos três anos, somadas à precipitação pluvial, foram de 345,0 mm no ambiente com estresse hídrico pósflorescimento, $445 \mathrm{~mm}$ no ambiente com estresse hídrico pré-florescimento e $600 \mathrm{~mm}$ no ambiente sem estresse hídrico.

O delineamento experimental utilizado foi de blocos casualizados, em esquema fatorial 2 x 16 (regimes de água $\mathrm{x}$ híbridos), com três repetições, em parcelas com quatro fileiras de $3 \mathrm{~m}$ de comprimento, sendo considerada área útil as duas fileiras centrais. A semeadura foi realizada de forma manual, sendo semeadas 20 sementes $\mathrm{m}^{-1}$. Aos 20 dias após a semeadura foi realizado um desbaste, deixando 10 plantas $\mathrm{m}_{\text {linear }}{ }^{-1}$, para obter um estande final de 200.000 plantas ha-1.

O preparo do solo foi realizado de forma convencional, com uma aração e duas gradagens em pré -plantio. A adubação foi realizada de acordo com os resultados de análise de solo e a exigência da cultu$\mathrm{ra}, 250 \mathrm{~kg} \mathrm{ha}^{-1}$ da fórmula 8-28-16 $\left(\mathrm{N}-\mathrm{P}_{2} \mathrm{O}_{5}-\mathrm{K}_{2} \mathrm{O}\right)$ no plantio, além de $72 \mathrm{~kg} \mathrm{ha}^{-1}$ de $\mathrm{N}$ em cobertura, usando como fonte nitrogenada a ureia, aos 30 dias após o plantio.

O rendimento de grãos foi obtido pela pesagem dos grãos colhidos na área útil de cada parcela, corrigindo-se a umidade para $13 \%$ e convertendo-se os dados para ton $\mathrm{ha}^{-1}$. Os índices de tolerância à seca por híbrido "i" foram calculados com base no rendimento de grãos por parcela para os ambientes com estresse hídrico (Ysi), sem estresse hídrico (Ypi) e significância do rendimento de grãos em condições de estresse (Ys) e sem estresse hídrico (Yp), como indicado na Tabela 1. A eficiência dos índices de seleção para tolerância à seca foi avaliada com base na sua capacidade de discriminação entre genótipos e correlação com o rendimento de grãos em ambos os ambientes.

Os dados de rendimento de grãos foram submetidos à análise de variância conjunta, considerando os efeitos dos genótipos, anos e ambientes, bem como a interação entre eles. Os efeitos dos genótipos foram considerados como fixos e os demais como aleatórios. Os ambientes em cada ano de cultivo foram comparados pelo teste F. Foi realizada a análise de correlação de Pearson entre os índices de seleção para cada ano de cultivo e o rendimento de grãos para avaliar as relações entre as variáveis.

O método GGE (Genotype main effects + Genotype environment interaction) Biplot (Yan et al., 2000), utilizando a análise dos componentes principais (PC), baseado em dados de matriz de correlação de classificação, foi utilizado para plotar os índices de seleção num único gráfico.

O dendograma foi utilizado para possibilitar visão bidimensional da similaridade ou dissimilarida- 
Tabela 1. Índices de seleção para tolerância à seca e fórmulas. Nova Porteirinha-MG, 2018.

\begin{tabular}{|c|c|c|}
\hline Índice & Fórmula & Referência \\
\hline Produtividade média (MP) & $(\mathrm{Ypi}+\mathrm{Ysi}) / 2$ & Rosielle e Hamblin (1981) \\
\hline Desempenho relativo médio (MRP) & $(Y s i / Y s)+(Y p i / Y p)$ & Hossain et al. (1999) \\
\hline Índice de suscetibilidade ao estresse (SSI) & $\begin{array}{c}1-(\mathrm{Ysi} / \mathrm{Ypi})) / \mathrm{SI}, \text { onde a } \\
\text { intensidade do estresse } \\
(\mathrm{SI})=1-(\mathrm{Ys} / \mathrm{Yp})\end{array}$ & Fischer e Maurer (1978) \\
\hline Índice de tolerância ao estresse (TOL) & Ypi - Ysi & Rosielle e Hamblin (1981) \\
\hline Produtividade média geométrica (GMP) & $\sqrt{ }($ Ypi x Ysi) & Fernandez (c1993) \\
\hline Índice de eficiência relativa (REI) & $(\mathrm{Ysi} / \mathrm{Ys}) *(\mathrm{Ypi} / \mathrm{Yp})$ & Hossain et al. (1999) \\
\hline Índice de tolerância ao estresse (STI) & $\left(\right.$ Ysi x Ypi) $/(Y p)^{2}$ & Fernandez (c1993) \\
\hline Média harmônica de rendimento (HM) & $2 *\left(Y p^{*} Y\right.$ si $) /(Y p i+Y s i)$ & Dadbakhsh et al. (2011) \\
\hline Índice de sensibilidade à seca (SDI) & (Ypi - Ysi) / Ypi & Farshadfar e Javadinia (2011) \\
\hline Índice relativo de seca (RDI) & (Ysi/Ypi) / (Ys/Yp) & Fischer e Wood (1979) \\
\hline Índice de resistência à seca (DI) & Ysi x (Ysi/Ypi) / (Ys) & Lan (1998) \\
\hline $\begin{array}{l}\text { Índices modificados de tolerância ao } \\
\text { estresse } 1 \text { (MSTIk1) }\end{array}$ & $\left((\mathrm{Ypi})^{2} /(\mathrm{Yp})^{2}\right) \times \mathrm{STI}$ & Farshadfar e Sutka (2002) \\
\hline $\begin{array}{c}\text { Índices modificados de tolerância ao } \\
\text { estresse } 2 \text { (MSTIk2) }\end{array}$ & $\left((\mathrm{Ysi})^{2} /(\mathrm{Ys})^{2}\right) \times \mathrm{STI}$ & Farshadfar e Sutka (2002) \\
\hline
\end{tabular}

Ysi e Ypi: rendimento de grãos para o genótipo "i” nas condições com e sem estresse hídrico, respectivamente; Ys e Yp: média do rendimento de grãos de todos os híbridos nas condições com e sem estresse hídrico, respectivamente.

de de todo o conjunto de amostras utilizado no estudo. O método de Ward foi utilizado para a confecção do dendograma. Este método consiste em procedimento de agrupamento hierárquico no qual a medida de similaridade usada para juntar agrupamentos é calculada como a soma de quadrados entre os dois agrupamentos feitos sobre todas as variáveis (Hair et al., 2005).

A análise de variância, o estudo de correlações e o agrupamento foram realizados com auxílio do Programa GENES (Cruz, 2013). Já a análise biplot foi desenvolvida com auxílio do pacote GGEGui implementado no software R (R Development Core Team, 2016).

\section{Resultados e Discussão}

A média do rendimento de grãos dos híbridos de sorgo granífero nos ambientes com estresse hídrico foi de 4,82 ton ha ${ }^{-1}$ em 2014, 2,26 ton ha- em 2015 e 2,43 ton ha ${ }^{-1}$ em 2017. Nos ambientes sem estresse hídrico, a média do rendimento de grãos foi de 7,48 ton ha-1, em 2014; 6,21 ton ha-1, em 2015; e 6,44, em 2017. O estresse hídrico reduziu o rendimento de 
grãos em 35\% em 2014, 64\% em 2015 e 62\% em 2017 (Figuras 4a, 4b e 4c). Dessa forma, o estresse hídrico foi moderado no ano de 2014 e severo nos anos de 2015 e 2017.

Com base na análise de variância conjunta houve diferença significativa para os genótipos, ambientes e anos, bem como para as interações entre eles. A maior magnitude de variação foi atribuída aos ambientes e aos anos, 86,98 e 10,26\%, respectivamente (Tabela 2).

Uma alta magnitude de variação para ambientes era esperada, considerando-se que uma mudança na condição hídrica apresentara efeito em diferentes proporções na produtividade de grãos dos genótipos de sorgo granífero (Tabela 2). A avaliação em diferentes anos contribuiu mais para a interação do que a avaliação de diferentes genótipos. A mudança dos fatores climáticos de um ano para o outro, principalmente da temperatura (Figuras 1, 2 e 3), proporciona grande influência no rendimento dos genótipos de sorgo granífero. Logo, os resultados deste trabalho comprovam a importância do estudo de campo em diferentes anos e/ou safras.

Os resultados da análise de variância conjunta dos índices de seleção para tolerância à seca revelam que o efeito do ano foi significativo para todos os índices, exceto para MRP, SSI, REI e RDI (Tabela 3). Esses resultados demonstram que o rendimento dos genótipos de sorgo foi influenciado pelas condições climáticas de cada ano e que os índices MRP, SSI, REI e RDI se mostraram os mais estáveis.

Apenas os índices MRP, REI e MSTIk2 não apresentaram diferença significativa para a interação GxA (Tabela 3). Esses índices não são desejáveis, pois na seleção de um índice espera-se a capacidade de distinção dos genótipos em diferentes ambientes. Os índices REI, STI, MSTIk1, MSTIk2 e DI apresentaram coeficientes de variação altos (acima de 30\%), o que não é desejável, pois, na seleção de um índice para tolerância à seca, espera-se que os melhores índices apresentem alta correlação com o rendimento nos ambientes com e sem estresse hídrico e baixo coeficiente de variação, aumentando assim a confiabilidade dos resultados.

A maior severidade do estresse hídrico em 2015 está associada a maiores temperaturas durante todo o período de indução do estresse hídrico (a partir de 45 dias após o plantio). Já em 2017, foram registradas maiores temperaturas no início da indução do estresse hídrico (Figuras 2 e 3). As maiores temperaturas au-

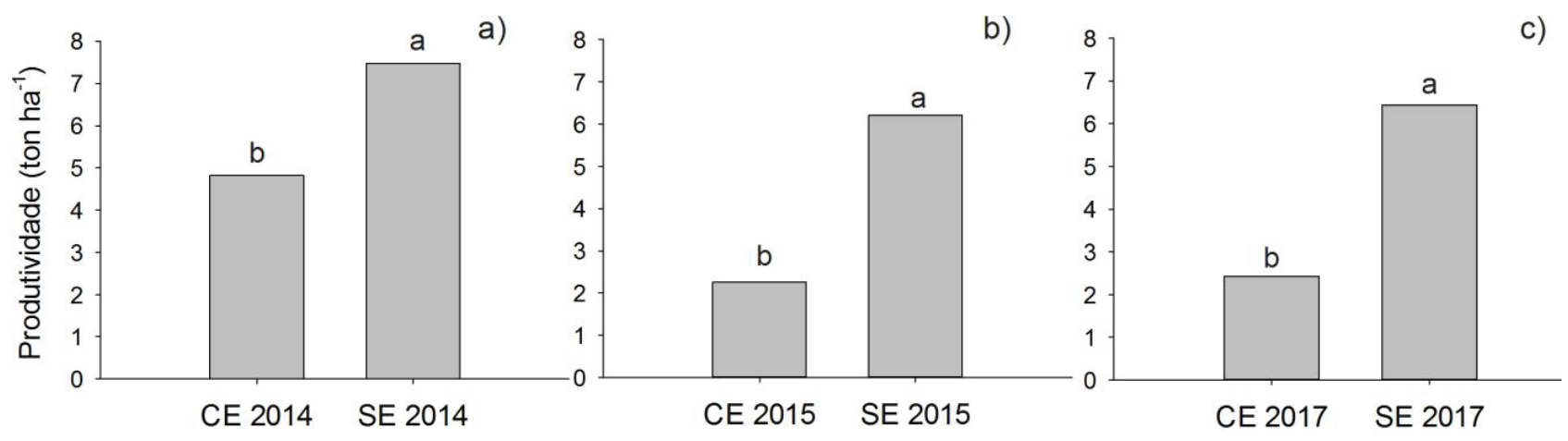

Figura 4. Produtividade de grãos nos ambientes com estresse hídrico (CE) e sem estresse hídrico (SE) nos anos de 2014, 2015 e 2017. Nova Porteirinha-MG.

'Médias seguidas de letras diferentes no ano diferem entre si pelo teste F a 5\% de significância 
Tabela 2. Análise de variância conjunta para o rendimento de grãos de genótipos de sorgo, em ambientes com e sem estresse hídrico, nos anos de 2014, 2015 e 2017. Nova Porteirinha-MG.

\begin{tabular}{cccc}
\hline FV & GL & QM & Porcentagem da variação explicada \\
\hline Bloco & 2 & $1,62^{\text {ns }}$ & 0,16 \\
Genótipo (G) & 15 & $7,84^{* *}$ & 0,75 \\
Ano (A) & 2 & $106,59^{* *}$ & 10,26 \\
Ambiente (E) & 1 & $903,27^{* *}$ & 86,98 \\
GxA & 30 & $1,59^{* *}$ & 0,15 \\
GxE & 15 & $1,54^{* *}$ & 0,15 \\
AxE & 2 & $13,99^{* *}$ & 1,35 \\
GxAxE & 30 & $1,54^{* *}$ & 0,15 \\
Erro & 190 & 0,55 & 0,05 \\
\hline CV (\%) & 14,96 & \\
\hline
\end{tabular}

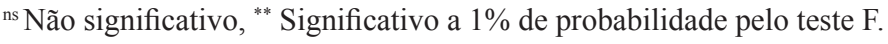

Tabela 3. Análise de variância do rendimento de grãos, nos ambientes com e sem estresse hídrico e dos índices de seleção para tolerância à seca, nos anos de 2014, 2015 e 2017. Nova Porteirinha-MG.

\begin{tabular}{ccccccc}
\hline \multirow{2}{*}{ FV/G1 } & Bloco & Genótipo $(\mathrm{G})$ & Ano $(\mathrm{A})$ & GxA & Erro & \multirow{2}{*}{ CV $(\%)$} \\
\cline { 2 - 5 } & 2 & 15 & 2 & 30 & 94 & \\
\hline Ys & $1,24^{\mathrm{ns}}$ & $3,79^{* *}$ & $98,56^{* *}$ & $1,45^{* *}$ & 0,62 & 24,9 \\
Yp & $1,04^{\mathrm{ns}}$ & $5,58^{* *}$ & $22,01^{* *}$ & $1,68^{* *}$ & 0,47 & 10,1 \\
MP & $0,80^{\mathrm{ns}}$ & $3,91^{* *}$ & $53,30^{* *}$ & $0,80^{* *}$ & 0,35 & 11,9 \\
MRP & $0,22^{\mathrm{ns}}$ & $0,79^{* *}$ & $0,00^{\mathrm{ns}}$ & $0,17^{\mathrm{ns}}$ & 0,11 & 16,6 \\
SSI & $0,08^{\mathrm{ns}}$ & $0,27^{* *}$ & $0,003^{\mathrm{ns}}$ & $0,18^{* *}$ & 0,06 & 24,2 \\
TOL & $1,31^{\mathrm{ns}}$ & $3,08^{* *}$ & $27,92^{* *}$ & $3,07^{* *}$ & 0,79 & 25,1 \\
GMP & $1,13^{\mathrm{ns}}$ & $4,32^{* *}$ & $76,18^{* *}$ & $1,00^{* *}$ & 0,48 & 15,4 \\
REI & $0,23^{\mathrm{ns}}$ & $0,76^{* *}$ & $0,001^{\mathrm{ns}}$ & $0,16^{\mathrm{ns}}$ & 0,12 & 33,7 \\
STI & $0,04^{\mathrm{ns}}$ & $0,16^{* *}$ & $1,25^{* *}$ & $0,04^{* *}$ & 0,02 & 30,4 \\
MSTIk1 & $0,15^{\mathrm{ns}}$ & $0,61^{* *}$ & $1,53^{* *}$ & $0,13^{* *}$ & 0,06 & 48,5 \\
MSTIk2 & $0,56^{\mathrm{ns}}$ & $1,08^{* *}$ & $1,09^{*}$ & $0,49^{\mathrm{ns}}$ & 0,32 & 86,9 \\
HM & $1,41^{\mathrm{ns}}$ & $4,64^{* *}$ & $96,17^{* *}$ & $1,29^{* *}$ & 0,64 & 19,2 \\
SDI & $0,02^{\mathrm{ns}}$ & $0,05^{* *}$ & $1,23^{* *}$ & $0,04^{* *}$ & 0,01 & 22,0 \\
RDI & $0,14^{\mathrm{ns}}$ & $0,25^{* *}$ & $0,005^{\mathrm{ns}}$ & $0,19^{* *}$ & 0,08 & 28,1 \\
DI & $0,11^{\mathrm{ns}}$ & $0,21^{* *}$ & $1,11^{* *}$ & $0,13^{* *}$ & 0,07 & 51,1 \\
\hline
\end{tabular}

ns Não significativo e ${ }^{* *}$, * Significativo a 1 e $5 \%$ de probabilidade, respectivamente, pelo teste F.

Índices: Média do rendimento de grãos na condição com estresse hídrico (Ys), média do rendimento de grãos na condição sem estresse hídrico (Yp), produtividade média (MP), desempenho relativo médio (MRP), índice de suscetibilidade ao estresse (SSI), índice de tolerância (TOL), produtividade média geométrica (GMP), índice de eficiência relativa (REI), índice de tolerância ao estresse (STI), média harmônica de rendimento (HM), índice de sensibilidade à seca (SDI), índice relativo de seca (RDI), índice de resistência à seca (DI) e índices modificados de tolerância ao estresse 1 e 2 (MSTIk1 e MSTIk2). 
mentaram os efeitos do estresse hídrico, acarretando maior redução da produtividade de grãos, por afetar, principalmente, o enchimento de grãos do sorgo.

O coeficiente de correlação de Pearson foi utilizado para determinar os índices de tolerância à seca mais desejáveis nas condições com e sem estresse hídrico. A análise de correlação revelou que nos três anos de avaliação houve associação positiva entre o rendimento de grãos nos ambientes com estresse hídrico (Ys) e sem estresse hídrico (Yp), entretanto foi significativa apenas em 2015 (Tabelas 4, 5 e 6). A baixa correlação entre Ys e Yp indica que os genótipos que apresentaram melhor desempenho produtivo nos ambientes sem estresse hídrico não necessariamente foram os mais produtivos nos ambientes com estresse. Estes resultados demonstram a dificuldade de seleção de genótipos que são tolerantes à seca e que apresentem também alto desempenho produtivo em condições hídricas ideais, pois os genótipos, em sua maioria, apresentam comportamento diferenciado em condições hídricas contrastantes.

No ano de 2014, o rendimento de grãos no ambiente com estresse hídrico (Ys) apresentou correlação altamente significativa e positiva com todos os índices estudados, excetuando-se SSI, TOL e SDI, que apresentaram correlação altamente significativa, porém negativa (Tabela 4). Em 2015 e 2017, quando o estresse hídrico foi mais severo, o comportamento da correlação para todos os índices com a Ys foi similar ao ano de 2014, porém, a correlação tornou-se predominantemente mais forte para os índices em 2015, ano em que o estresse hídrico proporcionou maior redução do rendimento de grãos dos genótipos de sorgo. No ano de 2017, correlação não significativa com Ys foi observada para os índices TOL e MSTIk1 (Tabela 5).

Correlações negativas de Ys com os índices TOL e SSI também foram relatadas por Kharrazi e
Rad (2011) e Abraha et al. (2015), avaliando índices de tolerância à seca em sorgo, indicando que quanto maior o valor desses índices, menor o rendimento de grãos dos genótipos de sorgo no ambiente com estresse hídrico (Ys). Sahar et al. (2016), avaliando índices de tolerância em trigo, também obtiveram correlações positivas e significativas dos índices MP, MRP, REI, GMP, STI, MSTIk1, MSTIk2, HM, RDI, DI com Ys. A alta correlação com rendimento de grãos em condições de estresse hídrico é muito desejada, considerando a grande dificuldade de seleção de caracteres que possam auxiliar na seleção daqueles que são de fato importantes, como a produtividade de grãos.

O rendimento de grãos no ambiente sem estresse hídrico (Yp), no ano de 2014, apresentou correlação positiva e altamente significativa com os índices MP, MRP, GMP, REI, STI, HM e MSTIk1, correlação positiva e moderada com o índice MSTIk2. A correlação entre os índices e Yp, em 2015, foi similar ao ano anterior, entretanto, diferentemente do que ocorreu com Ys, a correlação dos índices com Yp foi mais fraca, com exceção de MP (0,87 em 2014 e 0,88 em 2015). Já em 2017, a correlação dos índices de tolerância com o Yp continuou semelhante aos anos anteriores, porém, diferentemente dos anos anteriores, os índices SSI, TOL e SDI apresentaram correlação positiva e significativa com o Yp. Darvishzadeh et al. (2010) também relataram correlações significativas e positivas de Yp com MP, GMP, STI e HM, em trigo, e Menezes et al. (2014) encontraram correlações positivas e significativas dos índices GMP, SSI, MP, HM, TOL, STI e YI com Yp, em sorgo.

No geral, durante os três anos de cultivo, os índices de seleção MRP, MP, MSTIk1, GMP, REI, STI apresentaram as maiores magnitudes de correlação com o rendimento de grãos nos ambientes com e sem estresse hídrico. Porém, os índices MSTIk1, REI 
Tabela 4. Correlação de Pearson entre o rendimento de grãos e os índices de seleção em 2014. Nova Porteirinha-MG.

\begin{tabular}{|c|c|c|c|c|c|c|c|c|}
\hline Índices & Ys & $Y p$ & MP & MRP & SSI & TOL & GMP & REI \\
\hline Ys & 1 & & & & & & & \\
\hline$Y p$ & $0,49^{\mathrm{ns}}$ & 1 & & & & & & \\
\hline MP & $0,87^{* *}$ & $0,86^{* *}$ & 1 & & & & & \\
\hline MRP & $0,92^{* *}$ & $0,79^{* *}$ & $0,99^{* *}$ & 1 & & & & \\
\hline SSI & $-0,78^{* *}$ & $0,14^{\mathrm{ns}}$ & $-0,37^{\text {ns }}$ & $-0,49^{\mathrm{ns}}$ & 1 & & & \\
\hline TOL & $-0,52^{* *}$ & $0,49^{\mathrm{ns}}$ & $-0,02^{\text {ns }}$ & $-0,16^{\mathrm{ns}}$ & $0,92^{* *}$ & 1 & & \\
\hline GMP & $0,93^{* *}$ & $0,77^{* *}$ & $0,99^{* *}$ & $0,99^{* *}$ & $-0,51^{*}$ & $-0,18^{\mathrm{ns}}$ & 1 & \\
\hline REI & $0,93^{* *}$ & $0,76^{* *}$ & $0,98^{* *}$ & $0,99^{* *}$ & $-0,50^{*}$ & $-0,19^{\text {ns }}$ & $0,99^{* *}$ & 1 \\
\hline STI & $0,93^{* *}$ & $0,76^{* *}$ & $0,98^{* *}$ & $0,99^{* *}$ & $-0,50^{*}$ & $-0,18^{\mathrm{ns}}$ & $0,99^{* *}$ & $0,99^{* *}$ \\
\hline HM & $0,97^{* *}$ & $0,68^{* *}$ & $0,96^{* *}$ & $0,99^{* *}$ & $-0,60^{*}$ & $-0,30^{\mathrm{ns}}$ & $0,99^{* *}$ & $0,99^{* *}$ \\
\hline SDI & $-0,77^{* *}$ & $0,15^{\mathrm{ns}}$ & $-0,37^{\mathrm{ns}}$ & $-0,48^{\mathrm{ns}}$ & $0,99^{* *}$ & $0,92^{* *}$ & $-0,50^{*}$ & $-0,50^{*}$ \\
\hline RDI & $0,78^{* *}$ & $-0,14^{\mathrm{ns}}$ & $0,37^{\mathrm{ns}}$ & $0,48^{\mathrm{ns}}$ & $-0,99^{* *}$ & $-0,92^{* *}$ & $0,51^{*}$ & $0,50^{*}$ \\
\hline DI & $0,95^{* *}$ & $0,22^{\mathrm{ns}}$ & $0,69^{* *}$ & $0,77^{* *}$ & $-0,91^{* *}$ & $-0,74^{* *}$ & $0,78^{* *}$ & $0,79^{* *}$ \\
\hline MSTIk1 & $0,76^{* *}$ & $0,90^{* *}$ & $0,96^{* *}$ & $0,94^{* *}$ & $-0,22^{\mathrm{ns}}$ & $-0,12^{\mathrm{ns}}$ & $0,93^{* *}$ & $0,94^{* *}$ \\
\hline MSTIk2 & $0,93^{* *}$ & $0,56^{*}$ & $0,87^{* *}$ & $0,90^{* *}$ & $-0,61^{*}$ & $-0,38^{\mathrm{ns}}$ & $0,90^{* *}$ & $0,94^{* *}$ \\
\hline \multicolumn{9}{|c|}{ Continuação da tabela de correlações } \\
\hline & STI & $\mathrm{HM}$ & SDI & RDI & DI & MSTIk1 & MSTIk2 & \\
\hline STI & 1 & & & & & & & \\
\hline HM & $0,99^{* *}$ & 1 & & & & & & \\
\hline SDI & $-0,50^{*}$ & $-0,60^{*}$ & 1 & & & & & \\
\hline RDI & $0,50^{*}$ & $0,60^{*}$ & $-0,99^{* *}$ & 1 & & & & \\
\hline DI & $0,79^{* *}$ & $0,85^{* *}$ & $-0,91^{* *}$ & $0,91^{* *}$ & 1 & & & \\
\hline MSTIk1 & $0,92^{* *}$ & $0,86^{* *}$ & $-0,41^{*}$ & $0,38^{*}$ & $0,54^{* *}$ & 1 & & \\
\hline MSTIk2 & $0,94^{* *}$ & $0,92^{* *}$ & $-0,61^{*}$ & $0,61^{*}$ & $0,87^{* *}$ & $0,83^{* *}$ & 1 & \\
\hline
\end{tabular}

ns Não significativo e *, ** Significativo a 1 e $5 \%$ de probabilidade.

Índices: Média do rendimento de grãos na condição com estresse hídrico (Ys), média do rendimento de grãos na condição sem estresse hídrico (Yp), produtividade média (MP), desempenho relativo médio (MRP), índice de suscetibilidade ao estresse (SSI), índice de tolerância (TOL), produtividade média geométrica (GMP), índice de eficiência relativa (REI), índice de tolerância ao estresse (STI), média harmônica de rendimento (HM), índice de sensibilidade à seca (SDI), índice relativo de seca (RDI), índice de resistência à seca (DI) e índices modificados de tolerância ao estresse 1 e 2 (MSTIk1 e MSTIk2).

e STI apresentaram alto coeficiente de variação em comparação com os outros índices, o que inviabiliza a sua indicação na seleção de híbridos tolerantes ao estresse hídrico, pois esses índices apresentam alta dispersão dos dados. Os índices MP (produtividade média), GMP (produtividade média geométrica) e MRP (desempenho relativo médio) apresentaram menores coeficientes de variação e dentro do aceitável e, portanto, esses índices podem ser utilizados como critérios para auxiliar na seleção de híbridos com tolerância ao estresse hídrico e com alta produção de grãos, constituindo assim uma importante ferramenta em 
Tabela 5. Correlação de Pearson entre o rendimento de grãos e os índices de seleção em 2015. Nova Porteirinha-MG.

\begin{tabular}{|c|c|c|c|c|c|c|c|c|}
\hline Índices & Ys & $Y p$ & MP & MRP & SSI & TOL & GMP & REI \\
\hline YS & 1 & & & & & & & \\
\hline YP & $0,52^{*}$ & 1 & & & & & & \\
\hline MP & $0,88^{* *}$ & $0,87^{* *}$ & 1 & & & & & \\
\hline MRP & $0,97^{* *}$ & $0,72^{* *}$ & $0,97^{* *}$ & 1 & & & & \\
\hline SSI & $-0,95^{* *}$ & $-0,23^{\mathrm{ns}}$ & $-0,68^{* *}$ & $-0,84^{* *}$ & 1 & & & \\
\hline TOL & $-0,52^{*}$ & $0,45^{\mathrm{ns}}$ & $-0,05^{\mathrm{ns}}$ & $-0,30^{\mathrm{ns}}$ & $0,76^{* *}$ & 1 & & \\
\hline GMP & $0,97^{* *}$ & $0,72^{* *}$ & $0,97^{* *}$ & $0,99^{* *}$ & $-0,84^{* *}$ & $-0,29^{\mathrm{ns}}$ & 1 & \\
\hline REI & $0,96^{* *}$ & $0,72^{* *}$ & $0,97^{* *}$ & $0,99^{* *}$ & $-0,83^{* *}$ & $-0,29^{\mathrm{ns}}$ & $0,99^{* *}$ & 1 \\
\hline STI & $0,96^{* *}$ & $0,72^{* *}$ & $0,97^{* *}$ & $0,99^{* *}$ & $-0,83^{* *}$ & $-0,28^{\mathrm{ns}}$ & $0,99^{* *}$ & $0,99^{* *}$ \\
\hline HM & $0,99^{* *}$ & $0,62^{* *}$ & $0,92^{* *}$ & $0,99^{* *}$ & $-0,90^{* *}$ & $-0,41^{\mathrm{ns}}$ & $0,99^{* *}$ & $0,98^{* *}$ \\
\hline SDI & $-0,95^{* *}$ & $-0,23^{\mathrm{ns}}$ & $-0,68^{* *}$ & $-0,84^{* *}$ & $0,99^{* *}$ & $0,76^{* *}$ & $-0,84^{* *}$ & $-0,83^{* *}$ \\
\hline RDI & $0,95^{* *}$ & $0,23^{\mathrm{ns}}$ & $0,68^{* *}$ & $0,84^{* *}$ & $-0,99^{* *}$ & $-0,76^{* *}$ & $0,84^{* *}$ & $0,83^{* *}$ \\
\hline DI & $0,96^{* *}$ & $0,31^{\mathrm{ns}}$ & $0,74^{* *}$ & $0,88^{* *}$ & $-0,97^{* *}$ & $-0,69^{* *}$ & $0,87^{* *}$ & $0,88^{* *}$ \\
\hline MSTIk1 & $0,82^{* *}$ & $0,89^{* *}$ & $0,98^{* *}$ & $0,93^{* *}$ & $-0,59^{*}$ & $0,04^{\mathrm{ns}}$ & $0,92^{* *}$ & $0,94^{* *}$ \\
\hline MSTIk2 & $0,94^{* *}$ & $0,52^{*}$ & $0,81^{* *}$ & $0,92^{* *}$ & $-0,85^{* *}$ & $-0,54^{* *}$ & $0,90^{* *}$ & $0,93^{* *}$ \\
\hline \multicolumn{9}{|c|}{ Continuação da tabela de correlações } \\
\hline & STI & $\mathrm{HM}$ & SDI & RDI & DI & MSTIk1 & MSTIk2 & \\
\hline STI & 1 & & & & & & & \\
\hline HM & $0,98^{* *}$ & 1 & & & & & & \\
\hline SDI & $-0,82^{* *}$ & $-0,90^{* *}$ & 1 & & & & & \\
\hline RDI & $0,82^{* *}$ & $0,90^{* *}$ & $-0,99^{* *}$ & 1 & & & & \\
\hline DI & $0,87^{* *}$ & $0,92^{* *}$ & $-0,97^{* *}$ & $0,97^{* *}$ & 1 & & & \\
\hline MSTIk1 & $0,94^{* *}$ & $0,87^{* *}$ & $-0,59^{*}$ & $0,59^{*}$ & $0,67^{* *}$ & 1 & & \\
\hline MSTIk2 & $0,93^{* *}$ & $0,91^{* *}$ & $-0,85^{* *}$ & $0,85^{* *}$ & $0,94^{* *}$ & $0,82^{* *}$ & 1 & \\
\hline
\end{tabular}

ns Não significativo e *, ** Significativo a 1 e $5 \%$ de probabilidade.

Índices: Média do rendimento de grãos na condição com estresse hídrico (Ys), média do rendimento de grãos na condição sem estresse hídrico (Yp), produtividade média (MP), desempenho relativo médio (MRP), índice de suscetibilidade ao estresse (SSI), índice de tolerância (TOL), produtividade média geométrica (GMP), índice de eficiência relativa (REI), índice de tolerância ao estresse (STI), média harmônica de rendimento (HM), índice de sensibilidade à seca (SDI), índice relativo de seca (RDI), índice de resistência à seca (DI) e índices modificados de tolerância ao estresse 1 e 2 (MSTIk1 e MSTIk2).

programas de melhoramento para tolerância à seca. Os resultados deste trabalho estão de acordo com os obtidos por Golabadi et al. (2006) em trigo, Menezes et al. (2014) em sorgo, Shahrabian e Soleymani (2014) em milho.
A média de produtividade (MP) dos ambientes com e sem estresse hídrico é um índice muito utilizado na seleção de genótipos tolerantes à seca. Porém, a média pode não ser a melhor opção quando a interação GxA é significativa, em outras palavras, pode 
Tabela 6. Correlação de Pearson entre o rendimento de grãos e os índices de seleção em 2017. Nova Porteirinha-MG.

\begin{tabular}{|c|c|c|c|c|c|c|c|c|}
\hline & Ys & Yp & MP & MRP & SSI & TOL & GMP & REI \\
\hline YS & 1 & & & & & & & \\
\hline YP & $0,19^{\mathrm{ns}}$ & 1 & & & & & & \\
\hline MP & $0,54^{*}$ & $0,93^{* *}$ & 1 & & & & & \\
\hline MRP & $0,81^{* *}$ & $0,73^{* *}$ & $0,93^{* *}$ & 1 & & & & \\
\hline SSI & $-0,72^{* *}$ & $0,53^{* *}$ & $0,19^{\mathrm{ns}}$ & $-0,19^{\mathrm{ns}}$ & 1 & & & \\
\hline TOL & $-0,24^{\mathrm{ns}}$ & $0,90^{* *}$ & $0,68^{* *}$ & $-0,36^{\mathrm{ns}}$ & $0,84^{* *}$ & 1 & & \\
\hline GMP & $0,79^{* *}$ & $0,74^{* *}$ & $0,94^{* *}$ & $0,99^{* *}$ & $-0,15^{\mathrm{ns}}$ & $0,39^{\text {ns }}$ & 1 & \\
\hline REI & $0,78^{* *}$ & $0,76^{* *}$ & $0,94^{* *}$ & $0,99^{* *}$ & $-0,13^{\text {ns }}$ & $0,41^{\mathrm{ns}}$ & $0,99^{* *}$ & 1 \\
\hline STI & $0,78^{* *}$ & $0,75^{* *}$ & $0,94^{* *}$ & $0,99^{* *}$ & $-0,14^{\mathrm{ns}}$ & $0,40^{\mathrm{ns}}$ & $0,99^{* *}$ & $0,99^{* *}$ \\
\hline HM & $0,94^{* *}$ & $0,49^{*}$ & $0,78^{* *}$ & $0,95^{* *}$ & $-0,45^{\mathrm{ns}}$ & $0,07^{\mathrm{ns}}$ & $0,95^{* *}$ & $0,94^{* *}$ \\
\hline SDI & $-0,72^{* *}$ & $0,52^{*}$ & $0,18^{\mathrm{ns}}$ & $-0,19^{\text {ns }}$ & $0,99^{* *}$ & $0,84^{* *}$ & $-0,15^{\text {ns }}$ & $-0,13^{\mathrm{ns}}$ \\
\hline RDI & $0,72^{* *}$ & $-0,53^{*}$ & $-0,18^{\mathrm{ns}}$ & $0,19^{\mathrm{ns}}$ & $-0,99^{* *}$ & $-0,84^{* *}$ & $0,16^{\mathrm{ns}}$ & $0,14^{\mathrm{ns}}$ \\
\hline DI & $0,88^{* *}$ & $0,26^{\mathrm{ns}}$ & $0,11^{\mathrm{ns}}$ & $0,47^{\mathrm{ns}}$ & $-0,95^{* *}$ & $-0,64^{* *}$ & $0,43^{\mathrm{ns}}$ & $0,41^{\mathrm{ns}}$ \\
\hline MSTIk1 & $0,46^{\mathrm{ns}}$ & $0,92^{* *}$ & $0,97^{* *}$ & $0,87^{* *}$ & $0,24^{\mathrm{ns}}$ & $0,71^{\mathrm{ns}}$ & $0,89^{* *}$ & $0,91^{* *}$ \\
\hline MSTIk2 & $0,94^{* *}$ & $0,47^{\mathrm{ns}}$ & $0,76^{* *}$ & $0,94^{* *}$ & $-0,47^{\text {ns }}$ & $0,06^{\mathrm{ns}}$ & $0,92^{* *}$ & $0,92^{* *}$ \\
\hline \multicolumn{9}{|c|}{ Continuação da tabela de correlações } \\
\hline & STI & $\mathrm{HM}$ & SDI & RDI & DI & MSTIk1 & MSTIk2 & \\
\hline STI & 1 & & & & & & & \\
\hline HM & $0,94^{* *}$ & 1 & & & & & & \\
\hline SDI & $-0,14^{\mathrm{ns}}$ & $-0,46^{\mathrm{ns}}$ & 1 & & & & & \\
\hline RDI & $0,14^{\mathrm{ns}}$ & $0,46^{\mathrm{ns}}$ & $-0,99^{* *}$ & 1 & & & & \\
\hline DI & $0,42^{\mathrm{ns}}$ & $0,68^{* *}$ & $-0,95^{* *}$ & $0,95^{* *}$ & 1 & & & \\
\hline MSTIk1 & $0,90^{* *}$ & $0,71^{* *}$ & $0,24^{\mathrm{ns}}$ & $-0,23^{*}$ & $0,03^{\mathrm{ns}}$ & 1 & & \\
\hline MSTIk2 & $0,93^{* *}$ & $0,97^{* *}$ & $-0,47^{\mathrm{ns}}$ & $0,47^{\mathrm{ns}}$ & $0,71^{* *}$ & $0,70^{* *}$ & 1 & \\
\hline
\end{tabular}

ns Não significativo e *, ** Significativo a 1 e $5 \%$ de probabilidade.

Índices: Média do rendimento de grãos na condição com estresse hídrico (Ys), média do rendimento de grãos na condição sem estresse hídrico (Yp), produtividade média (MP), desempenho relativo médio (MRP), índice de suscetibilidade ao estresse (SSI), índice de tolerância (TOL), produtividade média geométrica (GMP), índice de eficiência relativa (REI), índice de tolerância ao estresse (STI), média harmônica de rendimento (HM), índice de sensibilidade à seca (SDI), índice relativo de seca (RDI), índice de resistência à seca (DI) e índices modificados de tolerância ao estresse 1 e 2 (MSTIk1 e MSTIk2).

ser muito influenciada por valores extremos de produtividade, principalmente do ambiente sem estresse hídrico, levando à seleção de genótipos com baixa produtividade no ambiente com estresse. Genótipos que apresentam grande discrepância de produtivida- de entre as duas condições hídricas podem apresentar a mesma média de genótipos que apresentam uma maior estabilidade na produção nos dois ambientes. Dessa forma, considerando apenas a média, erroneamente os dois genótipos seriam selecionados como 
tolerantes à seca e responsivos às condições hídricas ideais, pois um genótipo é estável e apresentou uma média produtiva alta nos dois ambientes e outro genótipo foi muito produtivo em um ambiente e no outro apresentou uma produção muito baixa. Logo, apenas o genótipo mais estável deveria ser selecionado como tolerante à seca e responsivo às melhorias nas condições hídricas.

Assim, os índices GMP (produtividade média geométrica) e MRP (desempenho relativo médio) que também apresentaram alta correlação com a produtividade nas duas condições hídricas podem ser utilizados na seleção de genótipos tolerantes à seca, pois corrigem o erro da seleção de híbridos com alta discrepância na produtividade entre os dois ambientes.

A seleção com base em uma combinação de índices pode ser mais útil para selecionar genótipos tolerantes à seca, porém o coeficiente de correlação de- termina o grau de associação linear apenas entre duas características. Assim, torna-se necessário uma abordagem melhor do que a análise de correlação, como a análise de biplot, para identificar genótipos superiores para os ambientes com e sem estresse hídrico. A partir da análise de componentes principais (PC) foi possível verificar as relações entre todos os índices, com base na classificação de correlação. No ano de 2014, os dois primeiros componentes principais (PC1 e PC2) explicaram 98,48\% da variação total, 73,03 e 25,45\%, respectivamente (Figura 5). Em 2015, os dois primeiros componentes principais explicaram $98,68 \%$ da variação total, 81,91 e 16,77\%, respectivamente (Figura 6). Em 2017, os dois primeiros componentes principais explicaram $99,18 \%$ da variação total, 60,60 e 38,58\%, respectivamente (Figura 7).

No biplot, índices plotados com coordenadas próximas a outros índices apresentam alta correlação

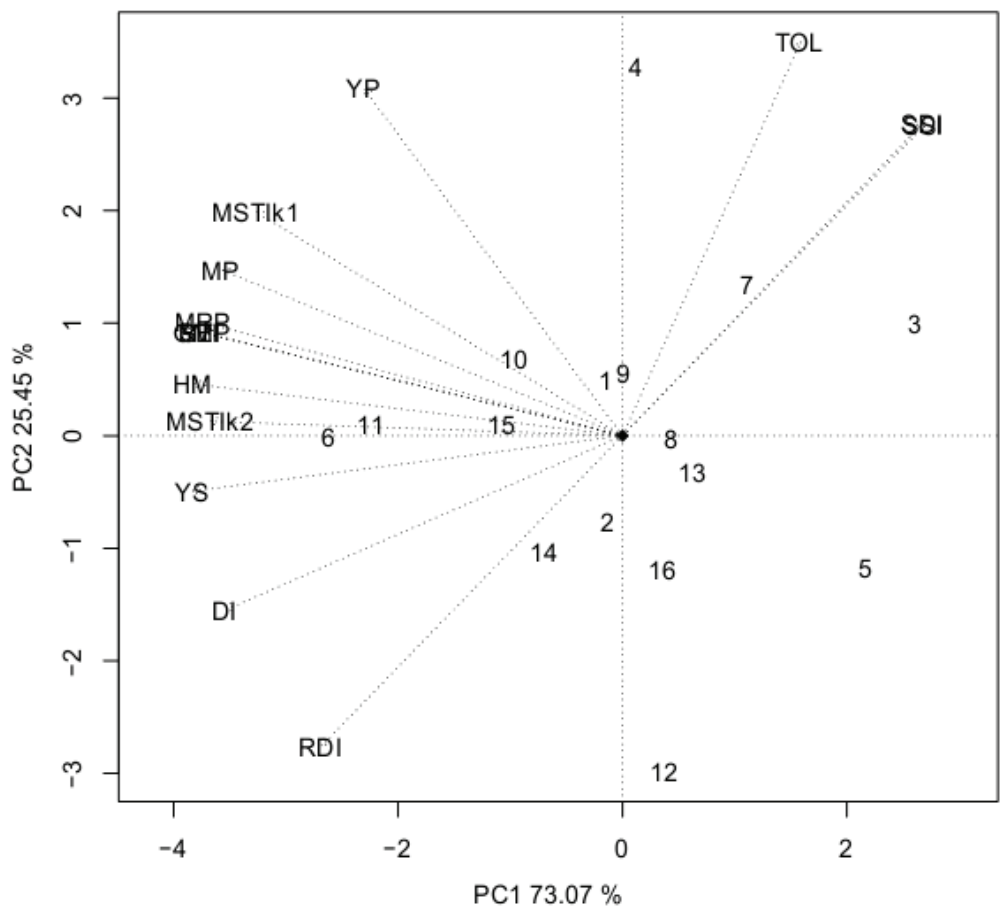

Figura 5. Relação entre os índices de seleção para tolerância à seca no ano de 2014, pelo modelo GGE biplot. Nova Porteirinha-MG. 


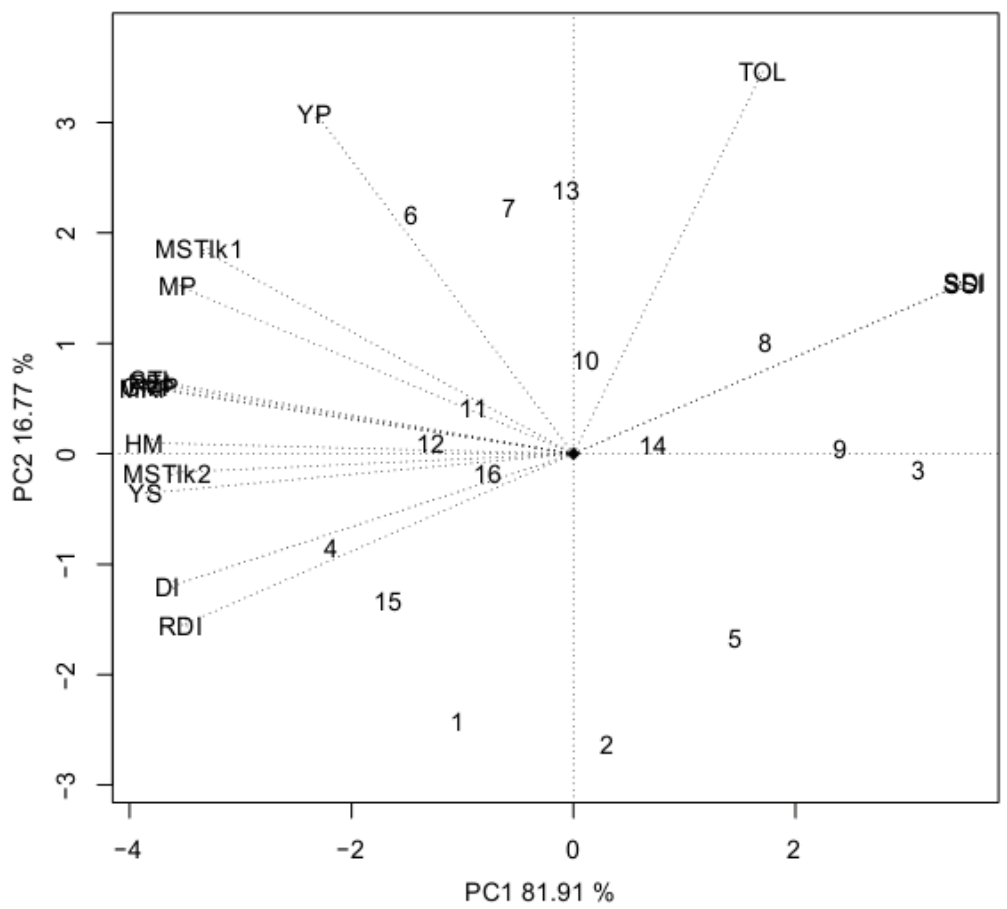

Figura 6. Relação entre os índices de seleção para tolerância à seca no ano de 2015, pelo modelo GGE biplot. Nova Porteirinha-MG.

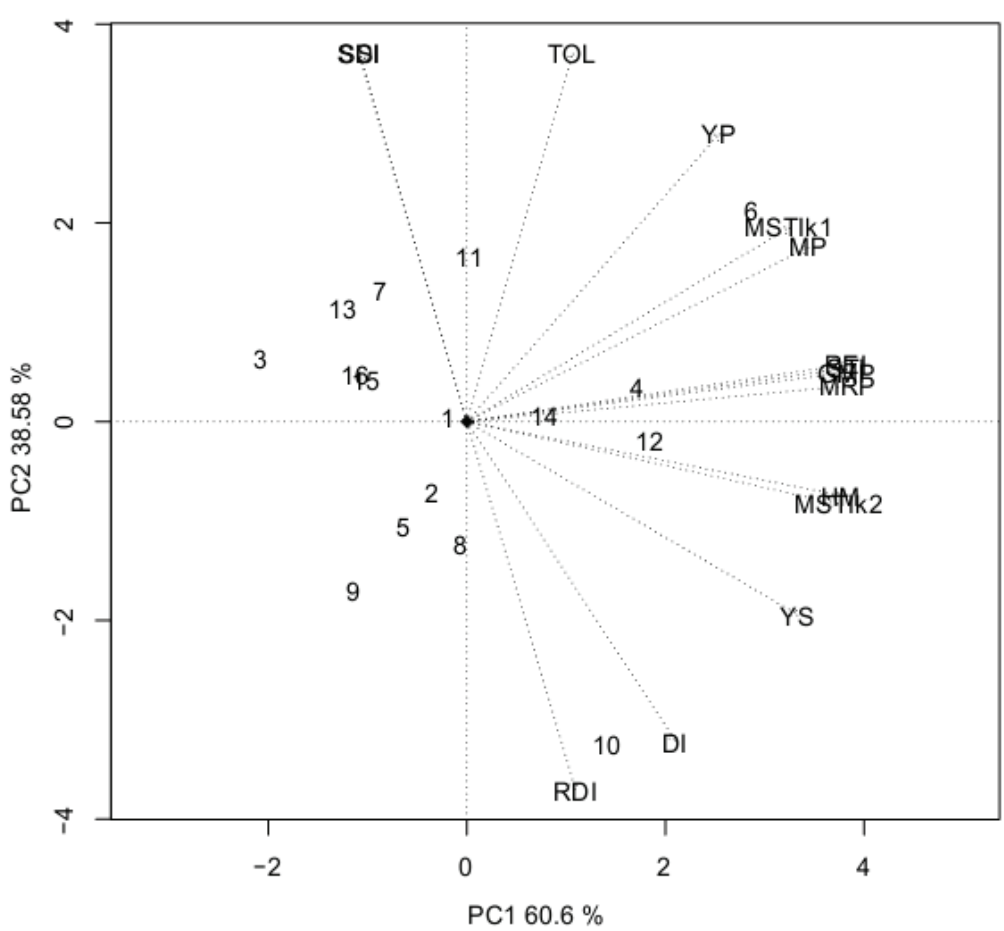

Figura 7. Relação entre os índices de seleção para tolerância à seca no ano de 2017, pelo modelo GGE biplot. Nova Porteirinha-MG. 


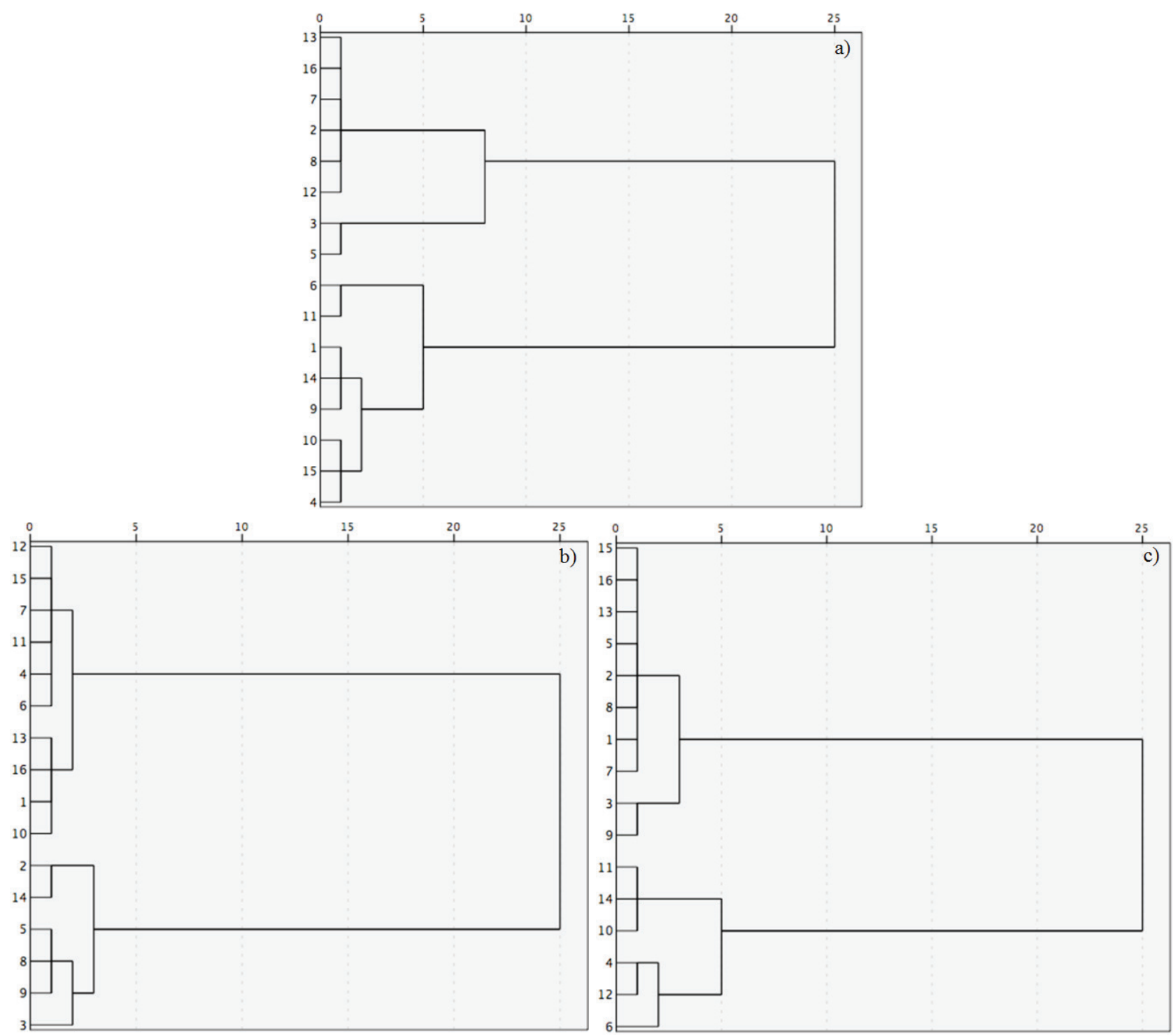

Figura 8. Dendrograma da análise de agrupamento usando ligação de Ward de genótipos de sorgo granífero baseados nos índices de tolerância à seca (MRP, MP e GMP) e na produtividade de grãos, em ambientes com e sem estresse hídrico, em Nova Porteirinha-MG, nos anos de 2014 (a), 2015 (b) e 2017 (c).

e semelhanças na classificação dos genótipos. Nos três anos de cultivo, os índices mais semelhanças com Ys foram DI, MSTIk2 e HM e com Yp foram os índices MSTIk1 e MP (Figuras 5, 6 e 7). O biplot mostra que em 2014, os híbridos 6 (1G 282) e 11 (AG
1090) apresentaram maior produtividade média nos ambientes com e sem estresse hídrico (Ys e Yp) e os genótipos 3 (BRS 332) e 5 (1G 220) apresentaram menor desempenho para esses ambientes (Figura 5). Em 2015, os genótipos 4 (1G 100), 12 (AS 4625), 
11 (AG 1090) e 6 (1G 282) apresentaram maior desempenho produtivo médio para os ambientes Ys e Yp (Figura 6). No ano de 2017, os genótipos 6 (1G 282), 4 (1G 100) e 12 (AS 4625) apresentaram maior produtividade média para os ambientes com e sem estresse hídrico (Figura 7).

Nos três anos de cultivo, os vetores para os índices MP, HM, MSTIk1, MSTIk2, STI, GMP, MRP e HM permaneceram entre os vetores Yp e Ys (Figuras 5, 6 e 7), indicando que esses índices são similares para a seleção de genótipos tolerantes à seca. Logo, os resultados obtidos através da análise biplot confirmam os resultados da análise de correlação.

Os índices MRP, MP e GMP, que apresentaram maior correlação com Yp e Ys e coeficiente de variação aceitável, foram utilizados para agrupar os genótipos em dendrograma, usando ligação de Ward (Figuras 8a, 8b e 8c). Os resultados do agrupamento foram muito consistentes com os obtidos na análise biplot.

A vantagem da análise com dendograma é calcular a distância entre genótipos. Em 2014, dentro do conjunto de genótipos superiores, 6 (1G 282) e 11 (AG 1090) foram 5 unidades de distância de outros membros do subgrupo (Figura 8a). Em 2015, o grupo de genótipos superiores, formado pelos genótipos 6 (1G 282), 4 (1G 100), 11 (AG 1090), 7 (50A10), 15 (BM 737) e 2 (BRS 330), foi duas unidades de distância do grupo mais próximo (Figura 8 b). No ano de 2017, os genótipos com rendimento de grãos superiores 6 (1G 282), 4 (1G 100) e 12 (AS 4625) apresentaram cinco unidades de distância dos outros membros do subgrupo (Figura 8c). Estes resultados indicam a superioridade desses genótipos e a eficiência dos índices MRP, MP e GMP para classificação de genótipos em condições com e sem estresse hídrico.

\section{Conclusões}

Os híbridos 1G282, $1 \mathrm{G} 100$ e AG1090 foram mais produtivos em condições com e sem estresse hídrico.

Os índices de seleção são úteis para seleção de genótipos de sorgo com rendimento desejável em condições com e sem estresse hídrico.

Os índices GMP e MRP são mais adequados para seleção de híbridos de sorgo granífero tolerantes ao estresse hídrico pós-florescimento.

\section{Agradecimentos}

À Embrapa Milho e Sorgo, ao Conselho Nacional de Desenvolvimento Científico e Tecnológico $(\mathrm{CNPq})$ e à Coordenação de Aperfeiçoamento de Pessoal de Nível Superior (Capes) pelos recursos financeiros e pelas bolsas para execução do projeto.

\section{Referências}

ABRAHA, T.; NYENDE, A. B.; MWANGI, S. G.; KASILI, R.; ARAIA, W. Identification of sorghum (Sorghum bicolor L. Moench) landraces tolerant to post flowering drought stress using drought tolerance indices. Journal of Plant Breeding and Crop Science, v. 7, n. 7, p. 211-218, 2015.

DOI: $10.5897 /$ jpbes2015.0521.

ACOMPANHAMENTO DA SAFRA BRASILEIRA [DE] GRÃOS: safra 2017/18: décimo levantamento. Brasília, DF: Conab, v. 5, n. 10, jul. 2018. 141 p.

BLUM, A. Sorghum physiology. In: NGUYEN, H. T.; BLUM, A. (Ed.). Physiology and biotechnology integration for plant breeding. New York: Marcel Dekker, 2004. p. 141-223. 
CRUZ, C. D. GENES: software package for analysis in experimental statistics and quantitative genetics. Acta Scientiarum, v. 35, n. 3, p. 271-276, 2013.

DOI: 10.4025 /actasciagron.v35i3.21251.

DADBAKHSH, A.; YAZDANSEPAS, A.; AHMADIZADEH, M. Study drought stress on yield of wheat (Triticum aestivum L.) genotypes by drought tolerance indices. Advances in Environmental Biology, v. 5, n. 8, p. 1804-1810, 2011.

DARVISHZADEH, R.; PIRZAD, A.; HATAMIMALEKI, H.; KIANI, S. P.; SARRAFI, A. Evaluation of the reaction of sunflower inbred lines and their F1 hybrids to drought conditions using various stress tolerance indices. Spanish Journal of Agricultural Research, v. 8, n. 4, p. 1037-1046, 2010. DOI: $10.5424 /$ sjar/2010084-1398.

FARSHADFAR, E.; SUTKA, J. Multivariate analysis of drought tolerance in wheat substitution lines. Cereal Research Communications, v. 31, n. 1, p. 33-40, 2002.

FARSHADFAR, E.; JAVADINIA, J. Evaluation of chickpea (Cicer arietinum L.) genotypes for drought tolerance. Seed and Plant Improvement Journal, v. 27, n. 4, p. 517-537, 2011.

FARSHADFAR, E.; ELYASI, P. Screening quantitative indicators of drought tolerance in bread wheat (Triticum aestivum L.) landraces. European Journal of Experimental Biology, v. 2, n. 3, p. 577$584,2012$.

FERNANDEZ, G. C. J. Effective selection criteria for assessing plant stress tolerance. In: KUO, C. G. (Ed.). Adaptation of food crops to temperature and water stress. Taipei: Asian Vegetable Research and Development Center, c1993. p. 257-270.

FISCHER, R. A.; MAURER, R. Drought resistance in spring wheat cultivars. Australian Journal of Agricultural Research, v. 29, n. 5, p. 897-912, 1978.

DOI: $10.1071 /$ AR9780897.
FISCHER, R. A.; WOOD, J. T. Drought resistance in spring wheat cultivars III. Yield association with morphological traits. Australian Journal of Agricultural Research, v. 30, p. 1001-1020, 1979.

GOLABADI, M.; ARZANI, A.; MAIBODY, S. A. M. Assessment of drought tolerance in segregating populations in durum wheat. African Journal of Agricultural Research, v. 1, n. 5, p. 162-171, 2006.

GOMES, F. P. Curso de estatística experimental. 15. ed. Piracicaba: ESALQ, 2009. 451 p.

HAIR, J. F.; BLACK, W. C.; BABIN, B. J.; ANDERSON, R. E.; TATAHN, R. L. Análise multivariada de dados. 5. ed. Porto Alegre: Bookman, 2005.

HOSSAIN, A. B. S.; SEARS, A. G.; COX, T. S.; PAULSEN, G. M. Desiccation tolerance and its relationship to assimilate partitioning in winter wheat. Crop Science, v. 30, n. 3, p. 622-627, 1999.

DOI: 10.2135/cropsci1990.0011183X003000030030x.

INSTITUTO NACIONAL DE METEOROLOGIA. Dados históricos. Disponível em: <http://www.inmet.gov.br/ portal/index.php? $\mathrm{r}=\mathrm{bdmep} / \mathrm{bdmep}>$. Acesso em: 3 jun. 2018.

KHARRAZI, M. A. S.; RAD, M. R. N. Evaluation of sorghum genotypes under drought stress conditions using some stress tolerance indices. African Journal of Biotechnology, v. 10, n. 61, p. 13086-13089, 2011.

KÖPPEN, W. Grundriss der Klimakunde: outline of climate science. Berlin: Walter de Gruyter, 1931. 388 p.

LAN, J. Comparison of evaluating methods for agronomic drought resistance in crops. Acta Agriculturae BorealiOccidentalis Sinica, v. 7, p. 85-87, 1998.

MENEZES, C. B.; TICONA-BENAVENTE, C. A.; TARDIN, F. D.; CARDOSO, M. J.; BASTOS, E. A.; NOGUEIRA, D. W.; PORTUGAL, A. F.; SANTOS, C. V.; SCHAFFERT, R. E. Selection indices to identify 
drought-tolerant grain sorghum cultivars. Genetics and Molecular Research, v. 13, n. 4, p. 9817-9827, 2014. DOI: $10.4238 / 2014$.November.27.9.

MOHAMMADI, R.; ARMION, M.; KAHRIZI, D.; AMRI, A. Efficiency of screening techniques for evaluating durum wheat genotypes under mild drought condition. International Journal of Plant Production, v. 4, n. 1, p. 11-24, 2010. DOI: 10.22069/ijpp.2012.677.

NOURI, A.; ETMINAN, A.; SILVA, J. A. T.; MOHAMMADI, R. Assessment of yield, yield-related traits and drought tolerance of durum wheat genotypes (Triticum turjidum var. durum Desf.). Australian Journal of Agricultural Research, v. 5, n. 1, p. 8-16, 2011.

R DEVELOPMENT CORE TEAM. R: a language and environment for statistical computing. Vienna: $\mathrm{R}$ Foundation for Statistical Computing, 2016. Disponível em: <http://www.R-project.org>. Acesso em: 3 jun. 2017.

REDDY, B. V. S.; RAMESH, S.; REDDY, P. S.; KUMAR, A. A. Genetic enhancement for drought tolerance in sorghum. Plant Breeding Reviews, v. 31, p. 189-222, 2009.

DOI: $10.1002 / 9780470593783 . c h 3$.

ROSIELLE, A. A.; HAMBLIN, J. Theoretical aspects of selection for yield in stress and non-stress environments. Crop Science, v. 21, n. 6, p. 943-946, 1981.

DOI: 10.2135/cropsci1981.0011183X002100060033x.
SAHAR, B.; AHMED, B.; NASERELHAQ, N.; MOHAMMED, J.; HASSAN, O. Efficiency of selection indices in screening bread wheat lines combining drought tolerance and high yield potential. Journal of Plant Breeding and Crop Science, v. 8, n. 5, p. 72-86, 2016.

SHAHRABIAN, E.; SOLEYMANI, A. Drought stress indices in some silage maize cultivars.

International Scholarly and Scientific Research \& Innovation, v. 8, n. 3, p. 291-295, 2014.

XIN, Z.; AIKEN, R.; BURKE, J. Genetic diversity of transpiration efficiency in sorghum. Field Crops Research, v. 111, n. 1/2, p. 74-80, 2009.

DOI: $10.1016 /$ j.fcr.2008.10.010.

XIONG, L.; WANG, R.; MAO, G.; KOCZAN, J. M. Identification of drought tolerance determinants by genetic analysis of root response to drought stress and abscisic acid. Plant Physiology, v. 142, n. 3, p. 1065-1074, 2006.

DOI: $10.1104 /$ pp.106.084632.

YAN, W.; HUNT, L. A.; SHENG, Q. L.; SZLAVNICS, Z. Cultivar evaluation and mega-environment investigation based on the GGE Biplot. Crop Science, v. 40, n. 3, p. 597-605, 2000.

DOI: $10.2135 /$ cropsci2000.403597x. 